\title{
Regimen Used to Treat Central Nervous System Neoplasm
}

National Cancer Institute

\section{Source}

National Cancer Institute. Regimen Used to Treat Central Nervous System Neoplasm. NCl Thesaurus. Code C140180.

Any regimen that can be used for the treatment of any type of central nervous system (CNS) neoplasm. 